\title{
Structural, Spectroscopic, and Photochemical Study of Ethyl Propiolate Isolated in Cryogenic Argon and Nitrogen Matrices
}

\author{
S. Lopes, ${ }^{*}$ T. Nikitin ${ }^{1}$ and Rui Fausto* \\ University of Coimbra, CQC, Department of Chemistry, 3004-535 Coimbra, Portugal
}

\begin{abstract}
Ethyl propiolate $\left(\mathrm{HC} \equiv \mathrm{CCOOCH}_{2} \mathrm{CH}_{3}, \mathrm{EP}\right)$ was studied experimentally by infrared spectroscopy in argon and nitrogen cryomatrices $(15 \mathrm{~K})$ and by quantum chemical calculations (at the DFT(B3LYP) and MP2 levels of theory). Calculations predict the existence of four conformers, two low-energy conformers (I and II) possessing the carboxylic moiety in the cis configuration $\left(\mathrm{O}=\mathrm{C}-\mathrm{O}-\mathrm{C}\right.$ dihedral equal to $\left.\sim 0^{\circ}\right)$ and two higherenergy trans forms $\left(\mathrm{O}=\mathrm{C}-\mathrm{O}-\mathrm{C}\right.$ dihedral equal to $\sim 180^{\circ}$; III and $\left.\mathbf{I V}\right)$. The conformation of the ethyl ester group within each pair of conformers is either anti $\left(\mathrm{C}-\mathrm{O}-\mathrm{C}-\mathrm{C}\right.$ equal to $180^{\circ}$; in conformers I and III) or gauche (C-O-C-C equal to $\pm 86.6^{\circ}$ in II, and $\pm 92.5^{\circ}$ in IV). The two low-energy cis conformers (I and $\mathbf{I I}$ ) were predicted to differ in energy by less than 2.5 $\mathrm{kJ} \mathrm{mol}^{-1}$ and were shown to be present in the studied cryogenic matrices. Characteristic bands for each one of these conformers were identified in the infrared spectra of the matrix-isolated compound and assigned taking into account the results of normal coordinate analysis, which used the geometries and harmonic force constants obtained in the DFT calculations. The two trans conformers (III and IV) were estimated to be at $17.5 \mathrm{~kJ} \mathrm{~mol}^{-1}$ higher in energy than the conformational ground state (form I) and were not observed experimentally.

The unimolecular photochemistry of matrix-isolated EP (in $\mathrm{N}_{2}$ matrix) was also investigated. In situ irradiation with UV light $(\lambda>235 \mathrm{~nm})$ leads mainly to decarbonylation of the compound, with generation of ethoxyethyne, which in a subsequent photoreaction generates ketene (plus ethene).
\end{abstract}

\section{Keywords}

Ethyl propiolate / Conformational analysis / Matrix isolation infrared spectroscopy / Photochemistry

\footnotetext{
*Corresponding authors e-mails: susylopes@qui.uc.pt; rfausto@ci.uc.pt

${ }^{1}$ Present address: University of Coimbra, CFisUC, Department of Physics, 3004-516 Coimbra, Portugal
} 


\section{INTRODUCTION}

Ethyl propiolate $\left(\mathrm{HC} \equiv \mathrm{CCOOCH}_{2} \mathrm{CH}_{3}, \mathrm{EP}\right)$ is the ethyl ester of propiolic acid consisting of an ethyl ester group attached to an acetylenic fragment $(\mathrm{H}-\mathrm{C} \equiv \mathrm{C}-)$. The compound is broadly used in organic synthesis, in particular in dipolar cycloaddition reactions leading to heterocycles such as pyrazoles, which possess a large range of applications in the pharmaceutical industry as well as in the agrochemical field, ${ }^{1-9}$ and as nucleophile in conjugate addition reactions such as those allowing selective carbon-carbon bond formation, which are particularly relevant in chemical synthesis and molecular design. ${ }^{10-13}$ The compound is also used as a derivatizing agent for the thiol group for the analysis of varietal thiols in wine. ${ }^{14-16}$

In spite of the practical relevance of the compound and the frequent references to EP in the context of organic synthesis, to the best of our knowledge up to now only the 1975 spectroscopic investigation of Charles et $a{ }^{17}{ }^{17}$ reported on its molecular structure and spectroscopic properties. Also, the photochemistry of the compound has not yet been addressed hitherto.

In their work, Charles and coworkers ${ }^{17}$ briefly discussed the infrared (IR) spectra of EP in the vapor, $\mathrm{CCl}_{4} / \mathrm{CS}_{2}$ solution, and crystalline phases and highlighted the fact that the IR spectrum obtained in solution exhibits some doublet-featured bands, indicating an occurrence of conformational isomerism. Taking into account information already known on the conformational preferences of other simple ethyl carboxylic esters (e.g., ethyl formate $)^{18}$ the authors suggested that the two conformers present in solution should have a cis carboxylic moiety $\left(\mathrm{O}=\mathrm{C}-\mathrm{O}-\mathrm{C}\right.$ dihedral angle equal to $\left.0^{\circ}\right)$ and differ by the conformation of the ethyl ester fragment (anti in one conformer and gauche in the other one, which correspond to $\mathrm{C}-\mathrm{O}-\mathrm{C}-\mathrm{C}$ dihedrals of $180^{\circ}$ and about $60^{\circ}$, respectively). ${ }^{17,18}$ These structural trends are in agreement with the presently known usual conformational behavior of simple carboxylic esters. ${ }^{19-25}$ Charles and coworkers presented assignments for the spectra of EP obtained in vapor, $\mathrm{CCl}_{4} / \mathrm{CS}_{2}$ solution, and crystalline phases and suggested the anti conformer (which corresponds to the sole form present in the crystalline material) as being the most stable EP conformer, though the relative energy of the two observed conformers could not be determined. ${ }^{17}$ Nevertheless, the authors stated that "from the appearance of the absorption bands, the values are probably of a similar order of magnitude to that found for ethyl formate", ${ }^{17}$ which was known to be $0.8 \pm$ $0.2 \mathrm{~kJ} \mathrm{~mol}^{-1} .^{18}$ 
In the present work, we report on the IR spectra of monomeric EP isolated in lowtemperature $(15 \mathrm{~K})$ argon and nitrogen matrices. The increased spectral resolution achieved under matrix isolation conditions was taken advantage of to identify the vibrational signatures of the two experimentally relevant conformers of the compound. The spectra were interpreted also with help of results obtained from a detailed theoretical investigation of the potential energy surface (PES) of EP (carried out using different basis sets at the DFT(B3LYP) and MP2 levels of theory), in particular the potential energy landscape defined by the internal rotations around the conformationally relevant $\mathrm{C}-\mathrm{O}$ bonds, and normal coordinate analysis. The unimolecular photochemistry of the matrix-isolated EP ( $\mathrm{N}_{2}$ matrix), induced by in situ broadband UV irradiation $(\lambda>235 \mathrm{~nm})$, was also investigated. As described in detail below, under the used experimental conditions, decarbonylation of the compound, leading to the generation of ethoxyethyne (which subsequently rearranges to ketene), corresponds to the observed major photochemical reaction.

\section{EXPERIMENTAL AND COMPUTATIONAL METHODS}

\subsection{Computational details}

The quantum chemical calculations were performed using the Gaussian 09 program package (Rev. A.02 and Rev. D.01) $)^{26,27}$ at the DFT(B3LYP) $)^{28-30}$ and MP2 ${ }^{31}$ levels of theory, using the 6-311++G(d,p), 6-311++G(3df,3pd), aug-cc-pVDZ, and aug-cc-pVTZ basis sets. ${ }^{32-}$

${ }^{39}$ A relaxed PES map representing energy as a function of the $\mathrm{O}=\mathrm{C}-\mathrm{O}-\mathrm{C}$ and $\mathrm{C}-\mathrm{O}-\mathrm{C}-\mathrm{C}$ dihedral angles was calculated at the DFT(B3LYP)/6-311++G(d,p) level of theory in order to locate the conformers of the molecule and transition states for conformational isomerizations, the latter being optimized using the synchronous transit-guided quasi-Newton (STQN) method. ${ }^{40}$ All geometries were optimized using the TIGHT convergence criteria of Gaussian 09, and the nature of all described stationary points was further characterized through the analysis of the corresponding Hessian matrices.

Calculated vibrational data was obtained at the DFT(B3LYP) /6-311++G(d,p) level of theory. The computed harmonic wavenumbers were scaled down by a single factor $(0.978)$ to correct them mainly for the effects of basis set limitations, neglecting part of electron correlation, and anharmonicity effects. The resulting wavenumbers together with the calculated IR intensities were used to simulate the spectra shown in the figures, through convolution with Lorentzian functions having a full-width-at-half-maximum (fwhm) equal to $2 \mathrm{~cm}^{-1}$. Normal 
coordinate analysis was undertaken in the internal coordinates space, as described by Schachtschneider and Mortimer, ${ }^{41}$ using the optimized geometries and harmonic force constants resulting from the DFT(B3LYP)/6-311++G(d,p) calculations. The internal coordinates used in this analysis were defined following the recommendations of Pulay et al. ${ }^{42}$

\subsection{Experimental details}

Ethyl propiolate was purchased from Sigma-Aldrich, spectroscopic grade. Prior to usage, the liquid samples were placed in a glass tube and connected to the vacuum chamber of a helium-cooled cryostat through a needle valve. Matrices were prepared by co-deposition of vapors of the compound together with a large excess of the matrix host-gas [Ar (N60) or $\mathrm{N}_{2}$ (N60)] onto a CsI substrate placed at the cold (15 K) tip of the cryostat (APD Cryogenics closed-cycle helium refrigeration system, with a DE-202A expander). The temperature of the CsI window was measured directly at the sample holder by a silicon diode sensor, connected to a digital temperature controller (Scientific Instruments, model 9650-1), which provides an accuracy of $0.1 \mathrm{~K}$. The valve nozzle was kept at room temperature $(298 \mathrm{~K})$ and the glass tube was kept at $\sim 157 \mathrm{~K}$ (immersed in ethanol and liquid nitrogen bath).

The IR spectra, in the $4000-400 \mathrm{~cm}^{-1}$ range, were obtained using a Thermo Nicolet 6700 Fourier transform infrared spectrometer, equipped with a deuterated triglycine sulfate (DTGS) detector and a Ge/KBr beam splitter, with $0.5 \mathrm{~cm}^{-1}$ spectral resolution. To avoid interference from atmospheric $\mathrm{H}_{2} \mathrm{O}$ and $\mathrm{CO}_{2}$, a stream of dry $\mathrm{CO}_{2}$-filtered air was continuously purging the optical path of the spectrometer.

Broadband irradiation of the matrices was carried out with UV light provided by a 500 W high-pressure $\mathrm{Hg}(\mathrm{Xe})$ lamp (Newport, Oriel Instruments), with output power set to $200 \mathrm{~W}$, through the outer $\mathrm{KBr}$ window of the cryostat $(\lambda>235 \mathrm{~nm}$, as defined by the onset of $\mathrm{KBr}$ transmission in UV).

\section{RESULTS AND DISCUSSION}

\subsection{Conformational analysis}

As already mentioned, the molecule of EP possesses two conformationally relevant degrees of freedom, corresponding to the internal rotations around its two $\mathrm{C}-\mathrm{O}$ bonds. Figure 1 presents the DFT(B3LYP)/6-311++G(d,p) calculated PES contour map for EP as a function of the $\mathrm{O}=\mathrm{C}-\mathrm{O}-\mathrm{C}$ and $\mathrm{C}-\mathrm{O}-\mathrm{C}-\mathrm{C}$ dihedral angles. In the calculations, these two dihedral angles 
were incremented in steps of $5^{\circ}$ and all remaining internal coordinates were optimized at each point.

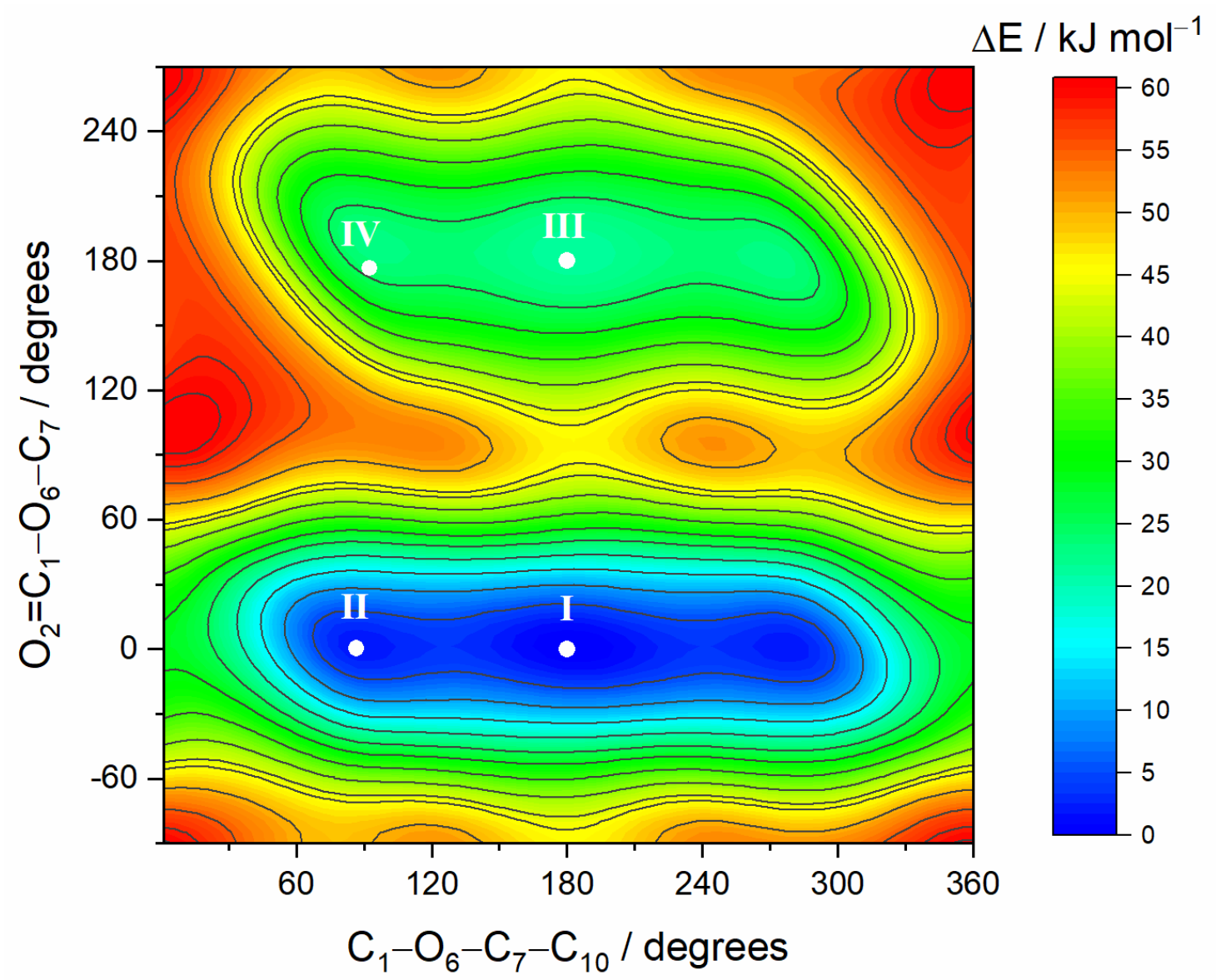

Figure 1. Relaxed potential energy surface contour map of EP calculated at the DFT(B3LYP)/6$311++\mathrm{G}(\mathrm{d}, \mathrm{p})$ level. The $\mathrm{O}=\mathrm{C}-\mathrm{O}-\mathrm{C}$ and $\mathrm{C}-\mathrm{O}-\mathrm{C}-\mathrm{C}$ dihedral angles were incremented in steps of $5^{\circ}$ and all remaining internal coordinates were optimized at each point. The location of the four conformers are indicated (I, II, III, and IV; for II and IV, equivalent-by-symmetry minima can also be seen in the map). The color bar designates the energy scale defined relative to the electronic energy of the lowestenergy form I (without the zero-point vibrational corrections). The isoenergy contour lines are traced using steps of $5 \mathrm{~kJ} \mathrm{~mol}^{-1}$.

Four non-symmetry-equivalent minima are observed in the contour map, corresponding to two $\mathrm{C}_{s}$ symmetry conformers (I and III) and two conformers with $\mathrm{C}_{l}$ symmetry (II and IV). Two additional minima are present in the PES, which correspond to the symmetry-equivalent degenerated forms of the $\mathrm{C}_{1}$ symmetry conformers.

The EP conformers are depicted in Figure 2. Forms I and II are low-energy conformers possessing the carboxylic moiety in the cis configuration $\left(\mathrm{O}=\mathrm{C}-\mathrm{O}-\mathrm{C}\right.$ dihedral equal to $0^{\circ}$ in conformer I and equal to $\pm 0.4^{\circ}$ in conformer II; DFT(B3LYP)/6-311++G(d,p) values), and correspond to the two conformers suggested by Charles and co-workers. ${ }^{17}$ These conformers differ by the geometry of the ester group, as defined by the $\mathrm{C}-\mathrm{O}-\mathrm{C}-\mathrm{C}$ dihedral angle, which is 
$180.0^{\circ}$ in conformer I (anti) and $\pm 86.6^{\circ}$ in II (gauche). Conformers III and IV are higherenergy trans forms $\left(\mathrm{O}=\mathrm{C}-\mathrm{O}-\mathrm{C}\right.$ dihedral equal to $180.0^{\circ}$ in $\mathbf{I I I}$ and $\pm 176.5^{\circ}$ in $\left.\mathbf{I V}\right)$ and are described here for the first time. The $\mathrm{C}-\mathrm{O}-\mathrm{C}-\mathrm{C}$ dihedral angle in III is $180^{\circ}$, while in IV it is $\pm 92.5^{\circ}$. The larger value for this dihedral angle in IV compared to II can easily be rationalized by taking into account the effect of the repulsive interaction between the ethyl ester substituent and the acetylenic fragment in conformer IV (see Figure 2).
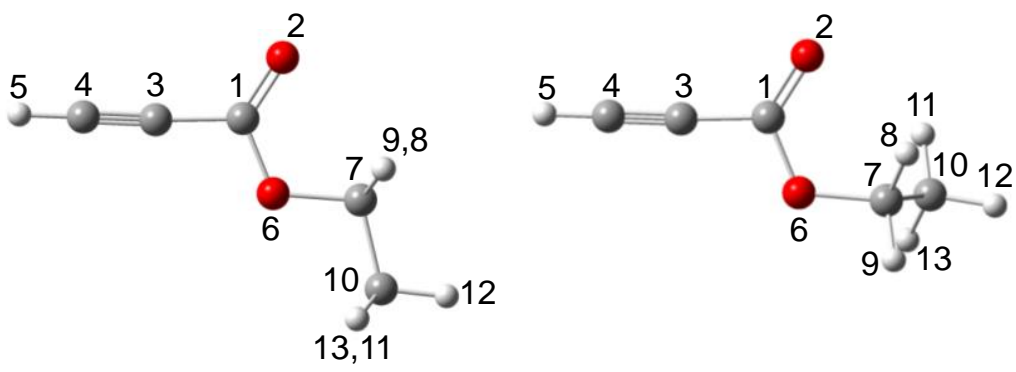

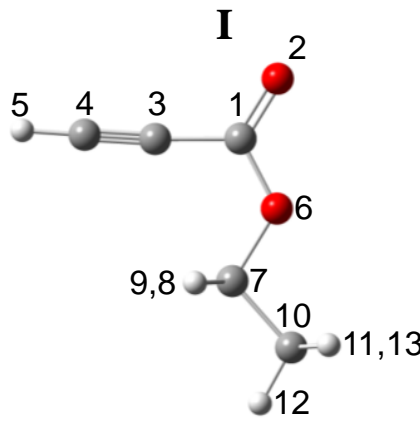

III

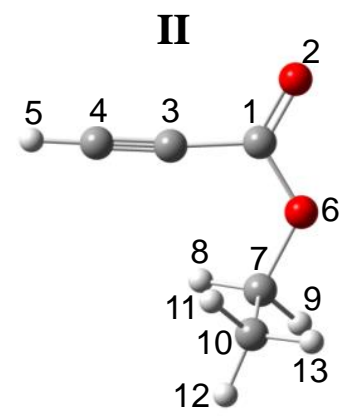

IV

Figure 2. DFT(B3LYP)/6-311++G(d,p) optimized structures of conformers I, II, III, and IV of ethyl propiolate, including the numbering of atoms adopted in this work. Colors: $\mathrm{C}-$ grey, $\mathrm{H}$-white, O-red.

The contour plot shown in Figure 1 also clearly reveals that the pairs of conformers, cis (I, II) and trans (III, IV), stay in valleys separated from each other by large energy barriers (higher than $45 \mathrm{~kJ} \mathrm{~mol}^{-1}$, taken as reference the energy of the most stable conformer $\mathbf{I}$; DFT(B3LYP)/6-311++G(d,p) values), while the interconversion barriers within the members of each pair are small (ca. $3 \mathrm{~kJ} \mathrm{~mol}^{-1}$ ). The two low-energy cis conformers (I and II) were predicted by the DFT(B3LYP)/6-311++G(d,p) calculations to differ in energy by $2.4 \mathrm{~kJ}$ $\mathrm{mol}^{-1}$, which is identical to the energy difference between the two higher-energy conformers obtained at this level of theory $\left(\Delta \mathrm{E}_{\mathbf{I V}-\mathrm{III}}=2.5 \mathrm{~kJ} \mathrm{~mol}^{-1}\right)$. Forms III and IV (trans) are higher in energy than the cis forms by $\sim 20 \mathrm{~kJ} \mathrm{~mol}^{-1}$.

The relative calculated energies for the four conformers obtained with the different combinations of method and basis set are presented in Table 1. 
Table 1. Electronic relative energies (including zero-point vibrational energy correction) calculated at the DFT(B3LYP) and MP2 levels of theory (with different basis sets) for the four conformers of EP.

\begin{tabular}{lllll}
\hline Method and basis set & $\begin{array}{l}\text { Conformers } \\
\text { I }\end{array}$ & II & III & IV \\
\hline DFT(B3LYP)/ & & & & \\
6-311++G(d,p) & 0.0 & 2.4 & 20.9 & 23.4 \\
6-311++G(3df,3pd) & 0.0 & 2.2 & 19.3 & 21.6 \\
aug-cc-pVDZ & 0.0 & 2.2 & 19.1 & 21.5 \\
aug-cc-pVTZ & 0.0 & 2.4 & 19.3 & 21.5 \\
\hline MP2/ & & & & \\
6-311++G(d,p) & 0.0 & 1.8 & 20.6 & 21.7 \\
6-311++G(3df,3pd) & 0.0 & 0.5 & 17.9 & 18.0 \\
aug-cc-pVDZ & 0.0 & 0.2 & 17.5 & 17.5 \\
aug-cc-pVTZ & 0.0 & 0.7 & 18.0 & 18.3 \\
\hline
\end{tabular}

From this table, it can be concluded that the relative energies obtained with the different methods and basis sets are very much consistent indicating that the numbers are reliable. The relative energy values found at the DFT(B3LYP) level, independently of the basis set used, are nearly equal, and they are also very similar to those obtained at the MP2 level, though in the latter case, the relative energy of the most stable conformer is predicted to be slightly higher when the 6-311++G(3df,3pd), aug-cc-pVDZ, and aug-cc-pVTZ basis sets are used. The values obtained with the $6-311++\mathrm{G}(\mathrm{d}, \mathrm{p})$ basis set are practically identical, independently of the method, DFT(B3LYP) or MP2.

The calculations indicate that conformers I and II shall be both considerably populated in the gas phase or in solution at room temperature, whereas conformers III and IV shall be non-relevant experimentally. Using the range of values predicted for the relative energy of II and $\mathbf{I}$ (from 0.2 to $2.4 \mathrm{~kJ} \mathrm{~mol}^{-1}$; see Table 1), and taking into account the multiplicity of the two conformational states ( 1 for $\mathbf{I}$ and 2 for the symmetry-degenerated conformer II), the Boltzmann equation leads to an estimation of the equilibrium room temperature relative population II:I that stays between $64.9 \%: 35.1 \%$ and $43.2 \%: 56.8 \%$. It is worth mentioning that the range of values for $\Delta$ EII-I calculated in the present study confirms the order of magnitude 
of the energy difference between the two conformers suggested by Charles and co-workers $(\sim 1$ $\left.\mathrm{kJ} \mathrm{mol}^{-1}\right){ }^{17}$

The energy barriers for conformational interconversions were also evaluated using both DFT(B3LYP) and MP2 methods and the different basis sets. The two sets of values are very similar, though the MP2 values tend to be slightly larger. The energy barrier for the I $\rightarrow$ II conversion is estimated to be $c a .3 .5$ and $5 \mathrm{~kJ} \mathrm{~mol}^{-1}$ (ca. 1 and $4 \mathrm{~kJ} \mathrm{~mol}^{-1}$ in the reverse direction) at DFT and MP2 levels, respectively; that associated with the III $\rightarrow$ IV conversion is predicted to be $\sim 2.8$ (DFT) and $\sim 4.1 \mathrm{~kJ} \mathrm{~mol}^{-1}$ (MP2) ( 0.4 and $\sim 3.7 \mathrm{~kJ} \mathrm{~mol}^{-1}$, respectively, in the reverse direction); the I $\rightarrow$ III barrier is estimated to be $c a .45$ (DFT) and 46 (MP2) kJ $\mathrm{mol}^{-1}$ ( 26 and $\sim 29 \mathrm{~kJ} \mathrm{~mol}^{-1}$ in the reverse direction); and, finally, the $\mathbf{I I} \rightarrow \mathbf{I V}$ energy barrier is predicted to be $\sim 46$ and $\sim 47 \mathrm{~kJ} \mathrm{~mol}^{-1}$ at DFT and MP2 levels, respectively ( 27 and $\sim 31 \mathrm{~kJ}$ $\mathrm{mol}^{-1}$ in the reverse direction).

The barrier between the two most stable conformers in the II $\rightarrow$ I direction is particularly relevant in the context of the present investigation. This barrier in the predicted range (1-4 $\left.\mathrm{kJ} \mathrm{mol}^{-1}\right)$ appears to be small enough to result in significant conformational cooling during the preparation of the low-temperature matrices, ${ }^{43-46}$ i.e., substantial conversion of the higher-energy conformer II into the most stable conformer I can be expected to take place due to local heating, upon landing of the EP molecules present in the "hot" gaseous beam onto the cold CsI substrate of the cryostat. One can thus expect conformer I to dominate in the matrices.

The optimized structural parameters (bond lengths and angles) for the four EP conformers, calculated using the different combinations of methods and basis sets, are given in Tables S1 and S2 (Supporting Information). On the whole, the values obtained at different calculation levels are in good agreement with each other, in particular in what concerns the most relevant structural differences between the conformers. The comparison of the calculated geometries of the four conformers can also be used to understand their relative stabilities.

Together with the repulsive interaction between the ethyl ester substituent and the acetylenic fragment present in the trans conformers, the main factor responsible for the stabilization of conformers I and II (cis) with respect to conformers III and IV (trans) is electrostatic in nature and results from the different relative orientation of the dipoles associated with the $\mathrm{C}=\mathrm{O}$ and $\mathrm{O}-\mathrm{C} 7$ bonds in the two types of conformers. In the cis forms, this alignment is nearly anti-parallel (attractive; stabilizing), while in the trans conformers it is approximately parallel (repulsive; destabilizing). A detailed analysis of this type of interaction has been made elsewhere. ${ }^{19-25}$ In addition to the bond-dipoles interactions, the cis conformers are further 
stabilized by the weaker non-classic H-bond-like interactions established between the carbonyl oxygen atom and the methylene hydrogen atoms of the ethyl ester substituent $(\mathrm{C}=\mathrm{O} \cdots \mathrm{H}-\mathrm{C})$. In conformer $\mathbf{I}$, there are two of these interactions $(\mathrm{O} \cdots \mathrm{H}$ distance $\sim 2.648 \AA$ ), while in conformer II there is only one $(\mathrm{O} \cdots \mathrm{H}$ distance $\sim 2.423 \AA$ ), this being the main factor responsible by the lower energy of I compared with II. A similar explanation can be given to justify the lower relative energy of III compared with IV, this time considering the number of stabilizing nonclassic H-bond-like interactions between the methylene hydrogen atoms and the triple bond $(\mathrm{C} \equiv \mathrm{C} \pi \cdots \mathrm{H}-\mathrm{C})$, which are two in conformer III and only one in form IV.

The above mentioned most relevant intramolecular interactions in terms of energy reflect in the relative values of the structural parameters (bond lengths and angles) that differ the most from conformer to conformer, in particular from cis type conformers (I, II) to the trans forms (III, IV). The $\mathrm{C}=\mathrm{O}$ bond length is longer in the cis conformers compared to that in the trans conformers (1.207/1.208 vs. $1.203 \AA$ at the DFT(B3LYP)/6-311++G(d,p) level). This reflects the increased polarization of the $\mathrm{C}=\mathrm{O}$ bond in the cis conformers due to the effect of the bond-dipole interactions and also non-classical $\mathrm{H}$-bond-like $\mathrm{C}=\mathrm{O} \cdots \mathrm{H}-\mathrm{C}$ interactions. In turn, the electronic charge flux in the $\mathrm{C}=\mathrm{O}$ bond, from $\mathrm{C}$ to $\mathrm{O}$, induces charge fluxes in the vicinal bonds towards the carbonyl carbon atom, so that in the cis conformers the $\mathrm{C}-\mathrm{O} 6$ and C1-C3 bonds are shorter than in the trans conformers (1.343 vs. $1.346 \AA$, in the case of the first bond, and $1.449 v s . \sim 1.455 / 1.456 \AA$ for the second). For the angles, the major differences are seen for the $\mathrm{C}-\mathrm{O}-\mathrm{C}\left(116.2 / 117.0\right.$ vs. $\left.121.2 / 122.2^{\circ}\right)$ and $\mathrm{C} 3-\mathrm{C} 1-\mathrm{O} 6\left(111.1 / 110.9^{\circ}\right.$ vs. 117.1/117. $6^{\circ}$ ), which are much larger in the trans conformers than those in the cis forms due to the effect of the repulsion between the ethyl ester substituent and the acetylenic fragment that is present in the first forms. The increase in the C3-C1-O6 angle in going from the cis to the trans conformers $\left(111.1 / 110.9\right.$ vs. $\left.117.1 / 117.6^{\circ}\right)$ is compensated by the reduction of the C$\mathrm{C}=\mathrm{O}$ and $\mathrm{O}=\mathrm{C}-\mathrm{O}$ angles, in particular the latter $\left(123.9 / 123.7\right.$ vs. $122.0 / 121.6^{\circ}$ and $125.0 / 125.3$ vs. $120.9 / 120.9^{\circ}$, respectively). It is also interesting to note that the O6-C7-C10 angles are substantially smaller for the planar forms, conformers I and III (107.4 and $107.1^{\circ}$, respectively) compared to the non-planar forms (conformers II and IV: $\sim 11.3$ and $111.1^{\circ}$ ), which is consistent with the existence of an attractive interaction between the methyl out-of-the-plane hydrogen atoms and the lone-electron pairs of the ester oxygen atom (O6). This interaction shall also contribute to the stabilization of conformers I and III in relation to their non-planar counterparts, II and IV, respectively. 


\subsection{Infrared spectra of matrix-isolated EP (as-deposited matrices)}

The experimental IR spectra of EP isolated in argon and nitrogen matrices (15 K) are presented in Figure 3. In the figure, the experimental spectra are compared with the theoretically simulated spectra of conformers I and II. Though the spectra of the two conformers are very similar, it was possible to identify bands in the experimental spectra belonging to the individual conformers. Moreover, the good agreement between the experimental and the calculated spectra allowed a straightforward assignment of the fundamental bands. In Table 2, the assignments are given using an approximate description, which was established based on the performed normal coordinate analysis. The full results obtained in these calculations are presented in Tables S3-S5 (Supporting Information).

As discussed above, since the energy difference between conformers I and II is small (in the range 0.2 to $2.4 \mathrm{~kJ} \mathrm{~mol}^{-1}$, according to the calculations; see Table 1) both conformers have significant populations in the room temperature gas phase equilibrium (predicted relative II:I population ratio in the range between $64.9 \%: 35.1 \%$ and $43.2 \%: 56.8 \%$.). However, as it was also pointed out before, the barrier for the conversion of II into I is small (between $c a$. 1 and $4 \mathrm{~kJ} \mathrm{~mol}^{-1}$ ), and the higher-energy conformer II can be expected to convert significantly into the lower-energy form I during deposition of the matrices. ${ }^{43-46}$ According to the expectations, the experimental spectra of the as-deposited matrices show that conformer I largely dominates in both matrices, the II:I population ratios in $\mathrm{Ar}$ and $\mathrm{N}_{2}$ matrices being $c a$. 1:4 and 1:2, respectively, as estimated from the relative intensity ratios of pairs of bands assigned to individual conformers with similar predicted IR intensities. Note that the predicted relative frequency of the conformers for the most intense band in the spectra, $v(\mathrm{CO})$, observed at $c a .1250 \mathrm{~cm}^{-1}$ is the opposite to that observed experimentally (see Figure 3). One can attribute this discrepancy to matrix interactions, which shall reflect the most in large IR intensity vibrations associated with more polarizable moieties and, consequently, very much sensitive to medium. 

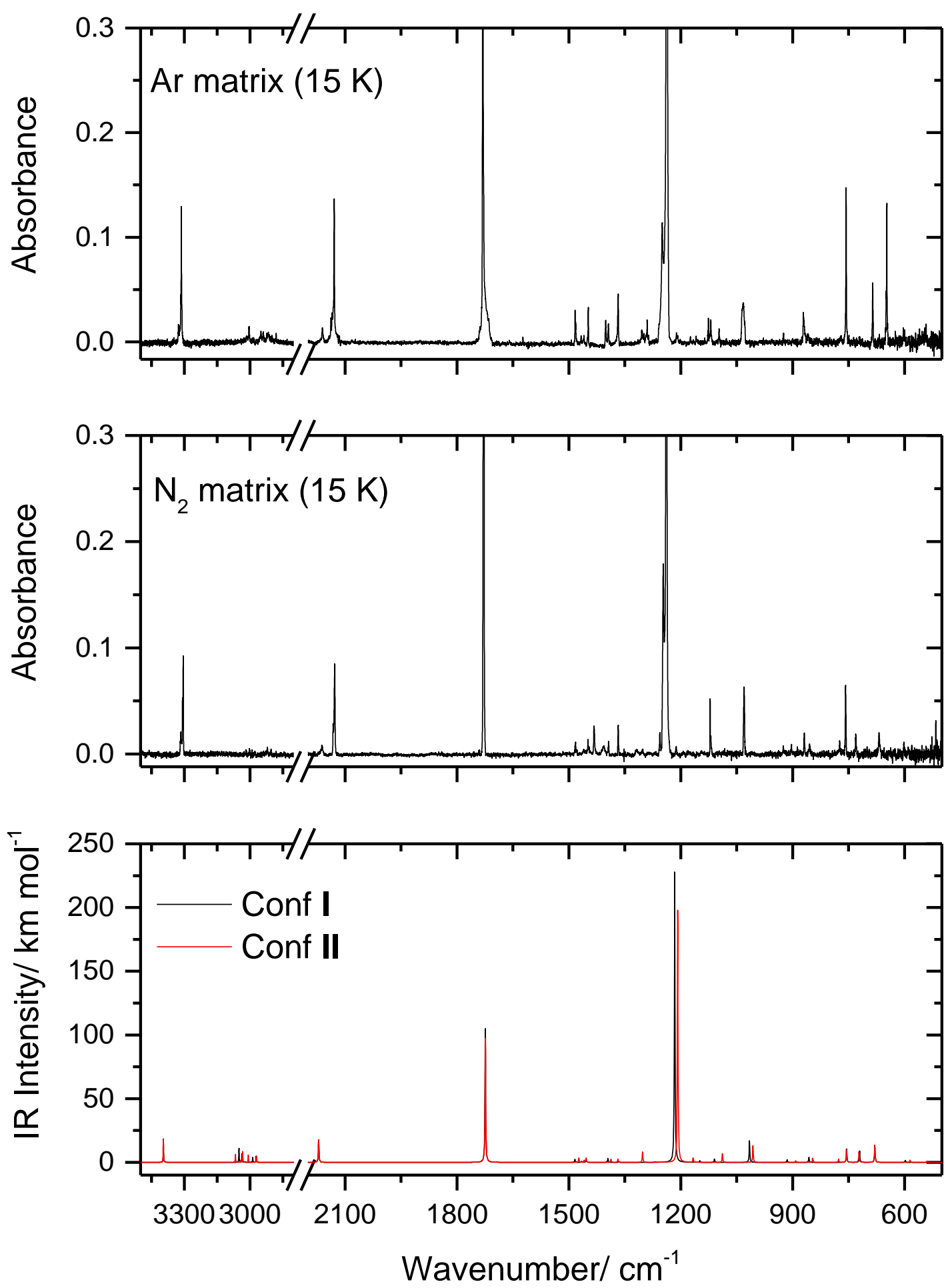

Figure 3. Experimental FTIR spectrum of EP isolated in $\mathrm{Ar}$ and $\mathrm{N}_{2}$ matrices at $15 \mathrm{~K}$ after deposition (top and middle), and DFT(B3LYP)/6-311++G(d,p) calculated infrared spectra for conformers I (black) and II (red). The calculated harmonic wavenumbers were scaled by 0.978 and the integral band intensities correspond to the calculated infrared absolute intensities. The most intense bands in the experimental spectra are truncated to allow the less intense bands to be clearly seen. 
Table 2. Experimental (matrix-isolation) and DFT(B3LYP)/6-311++G(d,p) calculated infrared data of conformers I and II of EP isolated in Ar and $\mathrm{N}_{2}$ matrices and vibrational assignments based on the results of normal coordinate analysis, and literature data. ${ }^{a}$

\begin{tabular}{|c|c|c|c|c|c|c|c|c|c|c|}
\hline $\begin{array}{l}\text { Approximate } \\
\text { Description }\end{array}$ & $\begin{array}{l}\text { Experimental } \\
\text { Argon matrix } \\
\text { Conf I }\end{array}$ & Conf II & $\begin{array}{l}\mathrm{N}_{2} \text { matrix } \\
\text { Conf I }\end{array}$ & Conf II & $\begin{array}{l}\text { Vapor } \\
\text { Ref.17 }\end{array}$ & $\begin{array}{l}\mathrm{CCl}_{4} / \mathrm{CS}_{2} \\
\text { solution } \\
\text { Ref.17 }\end{array}$ & $\begin{array}{l}\text { Calculated } \\
\text { Conf I }\end{array}$ & & Conf II & \\
\hline & $v$ & $v$ & $v$ & $v$ & $v$ & $v$ & $v$ & $\mathrm{I}^{\mathrm{IR}}$ & $v$ & $\mathrm{I}^{\mathrm{IR}}$ \\
\hline$v(\mathrm{CH})$ & 3322.0 & 3327.0 & 3317.0 & 3319.0 & 3333 & 3308 & 3395.7 & 59.1 & 3395.8 & 59.2 \\
\hline & 3314.5 & 3319.0 & 3305.5 & 3314.0 & 3328 & & & & & \\
\hline & 3311.5 & 3317.0 & & 3309.0 & 3322 & & & & & \\
\hline$v_{\mathrm{a}}\left(\mathrm{CH}_{3}\right)^{\prime \prime}, v_{\mathrm{a}}\left(\mathrm{CH}_{2}\right)$ & 3006.0 & 3014.5 & 3001.5 & 3019.0 & & & 3050.6 & 34.7 & 3066.9 & 20.1 \\
\hline$v_{a}\left(\mathrm{CH}_{3}\right)^{\prime}, v_{\mathrm{a}}\left(\mathrm{CH}_{3}\right)^{\prime \prime}$ & 2990.0 & n.obs. & 2990.0 & n.obs. & 2998 & & 3037.3 & 22.6 & 3042.5 & 4.6 \\
\hline$v_{a}\left(\mathrm{CH}_{2}\right), v_{a}\left(C_{3}\right)^{\prime}$ & n.obs. & 2985.0 & n.obs. & 2984.5 & & $\begin{array}{l}2985 \\
2966\end{array}$ & 3024.0 & 1.8 & 3033.8 & 28.2 \\
\hline$v_{\mathrm{s}}\left(\mathrm{CH}_{2}\right)$ & 2940.0 & 2950.0 & 2940.0 & 2952.0 & & $\begin{array}{l}2941 \\
2931\end{array}$ & 2988.2 & 13.0 & 3007.9 & 18.4 \\
\hline$v_{\mathrm{s}}\left(\mathrm{CH}_{3}\right)$ & 2922.5 & 2915.4 & 2920.0 & 2905.0 & & $\begin{array}{l}2908 \\
2875\end{array}$ & 2972.2 & 15.6 & 2970.2 & 15.6 \\
\hline$v(\mathrm{C} \equiv \mathrm{C})^{b}$ & $\begin{array}{l}2132.0 \\
2129.5\end{array}$ & $\begin{array}{l}2138.0 \\
2135.0\end{array}$ & $\begin{array}{l}2128.0 \\
2121.5\end{array}$ & $\begin{array}{l}2132.0 \\
2130.0\end{array}$ & $\begin{array}{l}2146 \\
2125\end{array}$ & $\begin{array}{l}2132(\text { II }) \\
2120(\text { I) }\end{array}$ & 2171.0 & 54.9 & 2170.9 & 56.7 \\
\hline$v(\mathrm{C}=\mathrm{O})$ & 1731.0 & $\begin{array}{l}1730.0 \\
1728.0\end{array}$ & $\begin{array}{l}1729.5 \\
1728.5\end{array}$ & 1727.5 & $\begin{array}{l}1746 \\
1736\end{array}$ & 1721 & 1724.1 & 333.2 & 1723.9 & 309.9 \\
\hline$\delta\left(\mathrm{CH}_{2}\right), \delta_{\mathrm{as}}\left(\mathrm{CH}_{3}\right)^{\prime}$ & 1483.5 & 1482.0 & 1483.5 & 1482.0 & & 1476 & 1483.8 & 8.1 & 1473.4 & 11.2 \\
\hline$\delta_{\mathrm{as}}\left(\mathrm{CH}_{3}\right)^{\prime}, \delta\left(\mathrm{CH}_{2}\right)$ & 1467.5 & 1459.5 & 1460.5 & 1449.0 & & 1466 & 1465.5 & 2.6 & 1459.4 & 5.1 \\
\hline$\delta_{\mathrm{as}}\left(\mathrm{CH}_{3}\right)^{\prime \prime \prime}$ & 1448.0 & 1448.0 & 1433.0 & 1433.0 & & 1446 & 1453.7 & 7.7 & 1454.2 & 10.8 \\
\hline$\delta_{\mathrm{s}}\left(\mathrm{CH}_{3}\right)$ & 1399.0 & 1394.0 & 1398.5 & 1393.5 & & 1389 & 1395.4 & 10.1 & 1387.3 & 8.3 \\
\hline wag $\left(\mathrm{CH}_{2}\right)$ & 1368.0 & 1368.0 & 1367.5 & 1367.5 & & 1366 & 1366.2 & 2.1 & 1368.5 & 8.3 \\
\hline $\operatorname{twist}\left(\mathrm{CH}_{2}\right)$ & 1258.0 & $\begin{array}{l}1305.0 \\
1303.5 \\
1290.5\end{array}$ & 1256.4 & $\begin{array}{l}1318.5 \\
1302.0\end{array}$ & & 1300 & 1269.5 & 0.9 & 1302.5 & 25.8 \\
\hline$v(\mathrm{CO})$ & 1238.0 & 1250.0 & 1251.5 & 1247.5 & & 1236 & 1216.4 & 720.3 & 1208.3 & 640.7 \\
\hline $\operatorname{rock}\left(\mathrm{CH}_{2}\right)$ & 1159.0 & 1174.5 & 1158.0 & 1180.0 & & & 1149.0 & 4.0 & 1166.9 & 10.8 \\
\hline $\operatorname{rock}\left(\mathrm{CH}_{3}\right)^{\prime}$ & $\begin{array}{l}1126.5 \\
1120.0\end{array}$ & 1097.5 & 1121.5 & 1119.0 & & $\begin{array}{l}1112(\mathbf{I}) \\
1096(\mathbf{I I})\end{array}$ & 1109.8 & 8.2 & 1088.4 & 22.1 \\
\hline$v\left(\mathrm{O}-\mathrm{CH}_{3}\right)$ & $\begin{array}{l}1034.5 \\
1032.5\end{array}$ & 1029.0 & 1030.0 & 1030.0 & $\begin{array}{l}1037 \\
1033 \\
1028\end{array}$ & 1023 & 1015.9 & 54.1 & 1006.6 & 42.0 \\
\hline$v(\mathrm{CC})$ & 924.5 & n.obs. & 925.5 & 903.0 & & $\begin{array}{l}923(\mathbf{I}) \\
900(\mathbf{I I})\end{array}$ & 914.9 & 6.6 & 891.9 & 3.7 \\
\hline$v\left(\mathrm{O}-\mathrm{CH}_{2}\right)$ & 871.5 & 860.0 & 869.0 & 853.0 & & 859 & 856.4 & 12.7 & 846.3 & 10.9 \\
\hline $\operatorname{rock}\left(\mathrm{CH}_{3}\right)^{\prime \prime \prime}$ & n.obs. & 771.0 & n.obs. & 774.5 & & 789 & 797.2 & 0.0 & 777.0 & 8.4 \\
\hline$\gamma(\mathrm{C}=\mathrm{O})$ & 757.0 & 757.0 & 758.0 & 758.0 & 756 & 753 & 755.4 & 33.0 & 755.8 & 32.3 \\
\hline$\gamma(\mathrm{C} \equiv \mathrm{C})$ & 686.0 & 686.0 & 730.0 & 730.0 & $\begin{array}{l}686 \\
680\end{array}$ & 689 & 720.5 & 27.9 & 722.2 & 27.9 \\
\hline
\end{tabular}




\begin{tabular}{|c|c|c|c|c|c|c|c|c|c|c|}
\hline$\delta(\mathrm{C} \equiv \mathrm{C})$ & 649.5 & 648.0 & 667.7 & 665.9 & $\begin{array}{l}674 \\
652 \\
642\end{array}$ & 652 & 679.9 & 42.9 & 679.8 & 43.4 \\
\hline$\delta(\mathrm{CC}=\mathrm{O})$ & 604.0 & n.obs. & 602.5 & 590.5 & 597 & $593(\mathbf{I})$ & 598.0 & 5.2 & 585.8 & 5.7 \\
\hline$\delta(\mathrm{OCC})$ & n.obs. & 542 (?) & $516(?)$ & n.obs. & $\begin{array}{l}551 \\
542\end{array}$ & & 516.2 & 0.5 & 539.7 & 3.2 \\
\hline$\delta\left(\mathrm{C}-\mathrm{O}-\mathrm{CH}_{3}\right)$ & n.i. & n.i. & n.i. & n.i. & $\begin{array}{l}388 \\
379\end{array}$ & 388 & 365.7 & 10.1 & 405.0 & 2.0 \\
\hline $\begin{array}{l}\gamma(\mathrm{CC}) \\
\delta\left(\mathrm{C}-\mathrm{O}-\mathrm{CH}_{2}\right)\end{array}$ & n.i. & n.i. & n.i. & n.i. & 325 & 328 (II) & 297.1 & 0.0 & 321.3 & 11.1 \\
\hline $\begin{array}{l}\delta\left(\mathrm{C}-\mathrm{O}-\mathrm{CH}_{2}\right) \\
\gamma(\mathrm{CC})\end{array}$ & n.i. & n.i. & n.i. & n.i. & 250 & $258(\mathbf{I})$ & 246.0 & 5.2 & 264.4 & 0.9 \\
\hline$\tau \mathrm{CH}_{3}$ & n.i. & n.i. & n.i. & n.i. & & & 242.9 & 0.5 & 219.9 & 1.6 \\
\hline$\delta(\mathrm{CC})$ & n.i. & n.i. & n.i. & n.i. & & 160 & 127.2 & 4.3 & 157.3 & 5.7 \\
\hline$\tau(\mathrm{CO})$ & n.i. & n.i. & n.i. & n.i. & & 135 & 118.7 & 4.7 & 91.5 & 1.4 \\
\hline$\tau(\mathrm{CO})^{\prime}$ & n.i. & n.i. & n.i. & n.i. & & 70 & 60.2 & 0.6 & 70.6 & 2.7 \\
\hline
\end{tabular}

${ }^{a}$ Wavenumbers $\left(\mathrm{cm}^{-1}\right.$, scaled by 0.978$)$, calculated intensities $\left(\mathrm{km} \mathrm{mol}^{-1}\right), \mathrm{s}=$ symmetric; a $=$ anti-symmetric; $v=$ stretching; $\delta=$ in-plane bending; $\gamma=$ out-of-plane bending; $\tau=$ torsion; rock = rocking, n.obs. = not observed; n.i. = not investigated. See Table S3 for definition of symmetry coordinates and Tables S4 and S5 for potential energy distributions. ${ }^{b}$ A small broad band is also observed at $2161(\mathrm{Ar})$ and $2162 \mathrm{~cm}^{-1}\left(\mathrm{~N}_{2}\right)$ which shall also be related with the $v(\mathrm{C} \equiv \mathrm{C})$ mode but whose precise assignment could not be established. 
The reason for the more efficient conformational cooling observed in the Ar matrix compared with the $\mathrm{N}_{2}$ matrix can be tentatively explained as resulting from the different thermal conductivities of solid $\mathrm{Ar}$ and $\mathrm{N}_{2}$. Since the latter is approximately twice of the former, local heating of the cold substrate at the place of landing of molecules being deposited is reduced in the $\mathrm{N}_{2}$ matrix, because thermal dissipation is facilitated. Under these circumstances, the locally available energy to surmount the energy barrier for the conversion of conformer II into I is less, and the conformational cooling is less efficient.

It is interesting also to note that the present results confirm the assignment by Charles and coworkers ${ }^{17}$ of the higher frequency component of the pairs of bands observed in solution at $1112 / 1096$ and $923 / 900 \mathrm{~cm}^{-1}$ to the anti conformer (I) and the lower component to the gauche form (II) (see Table 2). The lower frequency component disappears upon crystallization, indicating that in the crystal the molecules of EP assume the structure of conformer $\mathbf{I}$.

An additional observation that also agrees with the observations of Charles et al. ${ }^{17}$ concerns the high sensitivity of the frequencies of the $\delta(C \equiv C)$ and $\gamma(C \equiv C)$ modes to the medium. Accordingly, these two modes are those exhibiting the largest frequency shifts in going from the Ar to the $\mathrm{N}_{2}$ matrix, in particular, the $\gamma(\mathrm{C} \equiv \mathrm{C})$ vibration, which changes by almost $50 \mathrm{~cm}^{-1}$ (see Table 2).

Moreover, all bands observed in $\mathrm{Ar}$ and $\mathrm{N}_{2}$ matrices have counterparts in vapor or solution except for the $\operatorname{rock}\left(\mathrm{CH}_{2}\right)$ vibrational mode. Some of the bands were not observed in the vapor phase, for example, the band at $1236 \mathrm{~cm}^{-1}$ in solution assigned to the $\mathrm{CO}$ stretching mode is the most intense vibration, however has no counterpart in vapor.

Finally, the fact that the $v(\mathrm{CH})$ stretching bands (both in $\mathrm{Ar}$ and $\mathrm{N}_{2}$ matrices) show a multiplet profile shall also deserve here a brief comment. We performed annealing experiments (up to $34 \mathrm{~K}$ ) on the matrices to check if the spectra shown in Figure 3 contain bands due to aggregated species. The annealing experiments allowed us to conclude that aggregation is particularly visible in the $v(\mathrm{C}=\mathrm{O})$ and $v(\mathrm{CO})$ stretching regions of the spectra, where the aggregates give rise to broad intense bands with main maxima at 1718/1715 and $1280 / 1269 / 1261 / 1251 \mathrm{~cm}^{-1}$ respectively (values for $\mathrm{N}_{2}$ matrix; in argon, the corresponding bands appear at similar frequencies). These bands are absent in the spectrum shown in Figure 3 , showing that the spectra correspond only to those of the monomeric species. The observed band splitting in the $v(\mathrm{CH})$ stretching region is essentially due to matrix-site splitting, though Fermi resonance may also contribute to the splitting, since this effect has been observed for 
matrix-isolated acetylene. ${ }^{47}$ In the $v(\mathrm{CH})$ stretching spectral region, aggregation can be expected to give rise to broader bands appearing below $c a .3280 \mathrm{~cm}^{-1}$, as reported previously for acetylene complexes isolated in cryogenic matrices. ${ }^{47}$ Accordingly, in the annealed $\mathrm{N}_{2}$ matrix of ethyl propiolate, we observed a broad band with maxima at $c a .3250$ and $3220 \mathrm{~cm}^{-1}$, which can then be ascribed to aggregates of the compound.

\subsection{Photochemical experiments}

After irradiation of EP isolated in $\mathrm{N}_{2}$ matrix with UV light $(\lambda>235 \mathrm{~nm})$ using a highpressure $\mathrm{Hg} / \mathrm{Xe}$ arc lamp for $120 \mathrm{~min}$, approximately half of the EP initially present in the matrix was consumed, as shown by the changes of the IR intensities. New bands of photoproducts appear in the spectra of the irradiated matrix. Table 3 shows the experimentally observed bands of the photoproducts, together with the corresponding calculated data (at the DFT(B3LYP)/6-311++G(d,p) level) and previously reported literature data. ${ }^{48-52}$ Full calculated data for the observed photoproducts are provided in Tables S6-S9 (Supporting Information).

Characteristic intense bands of the photoproducts observed in the $2260-2100 \mathrm{~cm}^{-1}$ spectral region are presented in Figure 4, which shows the evolution of the spectrum in this region with the irradiation time. 
Table 3. Experimental (matrix-isolation) and DFT(B3LYP)/6-311++G(d,p) calculated infrared data for the observed photoproducts of EP in Ar in $\mathrm{N}_{2}$ matrices, vibrational assignments based on the results of normal coordinate analysis, and literature data. ${ }^{a}$

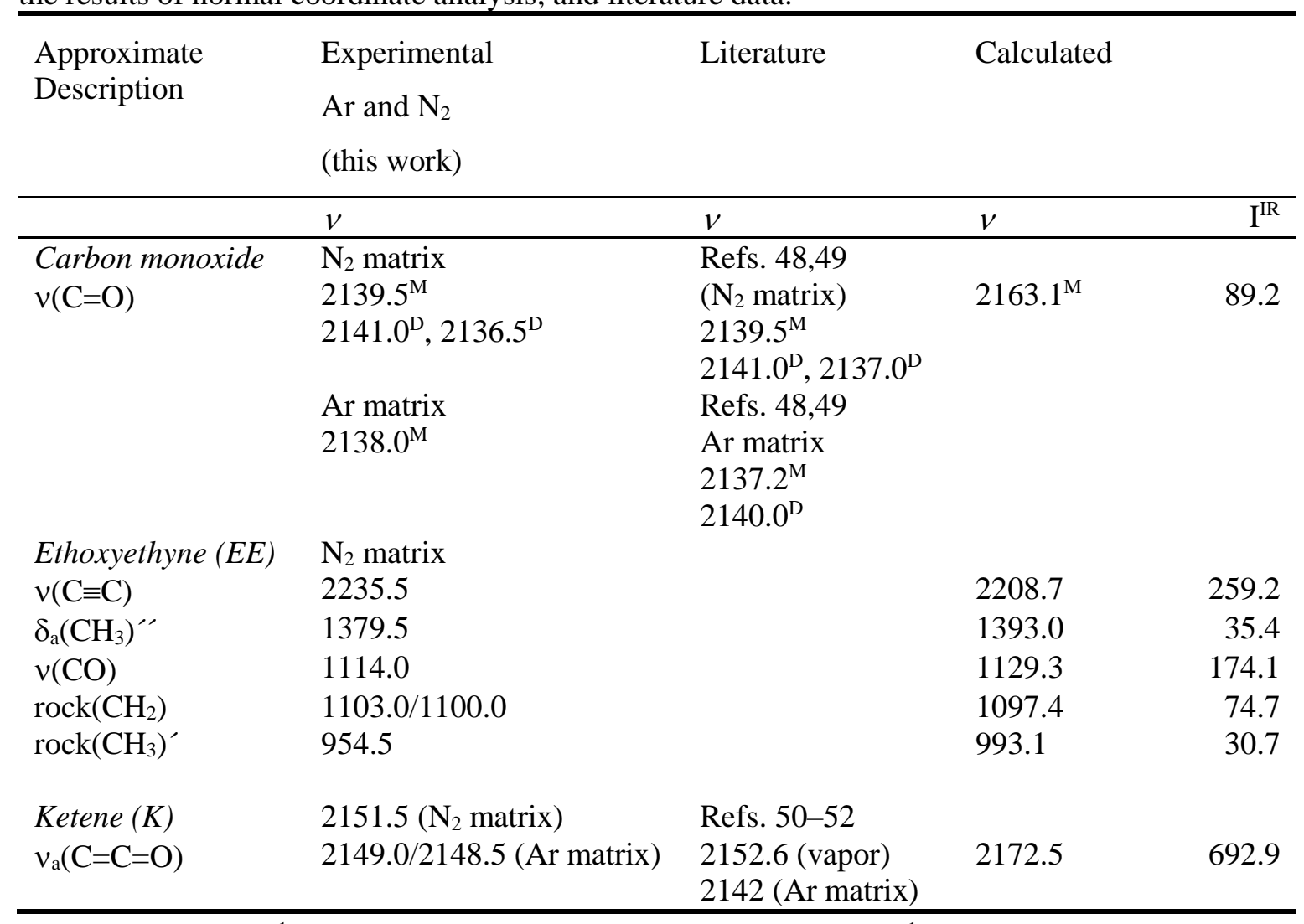

${ }^{a}$ Wavenumbers $\left(\mathrm{cm}^{-1}\right.$, scaled by 0.978$)$, calculated intensities $\left(\mathrm{km} \mathrm{mol}^{-1}\right), \mathrm{a}=$ anti-symmetric; $v=$ stretching; $\delta=$ in-plane bending; rock = rocking; $\mathrm{M}=$ monomer; $\mathrm{D}=$ dimer. See Tables S6-S9 for complete set of calculated data.

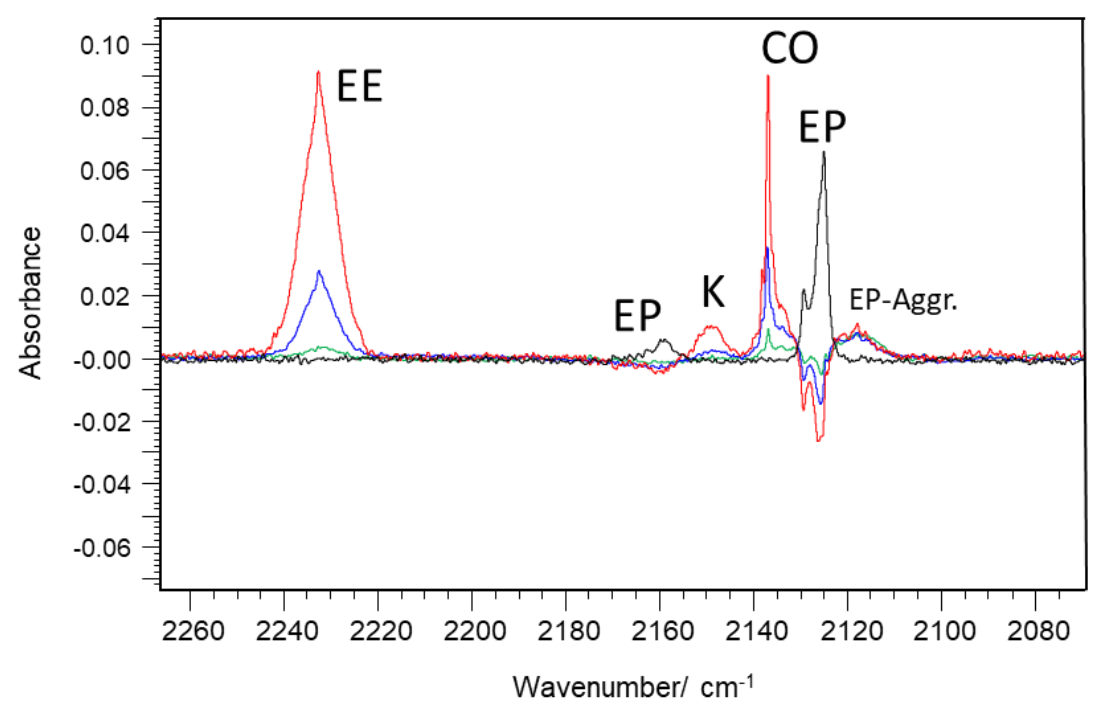

Figure 4. Experimental IR spectra of EP isolated in $\mathrm{N}_{2}$ matrix at $15 \mathrm{~K}$ after deposition (in black) and difference spectra resulting from subtracting that spectrum from those obtained after UV irradiation $(\lambda>235 \mathrm{~nm}$ ) of the matrix-isolated EP for 15, 60, and 120 min (green, blue, and red, respectively). EE: ethoxyethyne; K: ketene. 
Identification of characteristics bands due to monomeric carbon monoxide $(\mathrm{CO})$ at $2139.5 \mathrm{~cm}^{-1}$ and dimer (minor peaks at 2141.0 and $2136.5 \mathrm{~cm}^{-1}$ ) 48,49 allowed to conclude on the occurrence of decarbonylation of EP (Figure 5). Together with $\mathrm{CO}$, ethoxyethyne $\left(\mathrm{HC} \equiv \mathrm{COCH}_{2} \mathrm{CH}_{3} ; \mathrm{EE}\right)$ shall be formed and, accordingly, bands due to this compound are observed in the spectra of the irradiated matrix, specifically the predicted most intense bands: the strongest band is observed at $2235.5 \mathrm{~cm}^{-1}$ (see Figure 4) and is assigned to the $\mathrm{C} \equiv \mathrm{C}$ stretching vibration of EE (predicted at $2208.7 \mathrm{~cm}^{-1}$ ), while the bands observed at 1379.5, 1114.0, 1103.0/1100.0, and $954.5 \mathrm{~cm}^{-1}$ correspond to the $\delta_{\text {as }}\left(\mathrm{CH}_{3}\right)^{\prime \prime}, v(\mathrm{CO}), \operatorname{rock}\left(\mathrm{CH}_{2}\right)$, and $\operatorname{rock}\left(\mathrm{CH}_{3}\right)^{\prime}$ vibrations (predicted at 1393.0, 1129.3, 1097.4, and $993.1 \mathrm{~cm}^{-1}$ ), respectively.

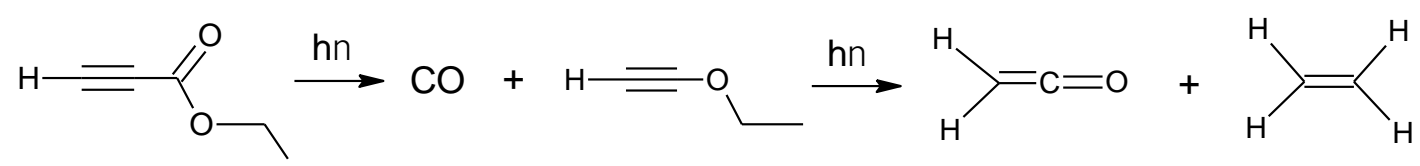

Figure 5. Observed photochemical reactions upon UV light $(\lambda>235 \mathrm{~nm})$ irradiation of EP isolated in an $\mathrm{N}_{2}$ matrix $(15 \mathrm{~K})$.

In Figure 4, two additional smaller bands are also shown. The first, observed at 2120 $\mathrm{cm}^{-1}$, is due to aggregates of EP. It can be seen that aggregation of EP was negligible and took place only in the initial states of irradiation. The second band is observed at $2151.5 \mathrm{~cm}^{-1}$ and starts to grow visibly only after $\sim 20$ minutes of irradiation, suggesting its origin in a secondary photoproduct.

The dynamics of the photodissociation of EE at $193 \mathrm{~nm}$ has been previously reported, namely describing EE as an efficient photolytic precursor of ketenyl radical which acts as an intermediate in a wide range of combustion reactions. ${ }^{53-55}$ Though irradiation in the present study has been carried on at longer wavelengths, it appears still possible that the initially photoproduced EE subsequently fragments into ketene $\left(\mathrm{H}_{2} \mathrm{C}=\mathrm{C}=\mathrm{O} ; \mathrm{K}\right)$ and ethene $\left(\mathrm{H}_{2} \mathrm{C}=\mathrm{CH}_{2}\right)$ (Figure 5). Under the conditions of our experiments, the process has very low efficiency, as inferred from the low experimental infrared intensity of the anti-symmetric $\mathrm{C}=\mathrm{C}=\mathrm{O}$ stretching vibration of the ketene (the band at $2151.5 \mathrm{~cm}^{-1}$ observed in Figure 4). This vibration is known to give rise to a very intense band (see also Supporting Information Table S9) and has been observed before at $2152.8 \mathrm{~cm}^{-1}$ in the gas phase in several publications, including Duncan et 
al. and Moore and Pimentel. ${ }^{50-52}$ No bands ascribable to ethene could be detected in the photolyzed matrix, but this could be anticipated because this compound does not exhibit any strong IR band in a spectroscopic clean region. ${ }^{56}$

\section{CONCLUSION}

In the present work, ethyl propiolate was investigated by IR spectroscopy in argon and nitrogen matrices and by quantum chemical calculations carried out at the DFT and MP2 levels of theory. The complete assignment of the spectra was undertaken, revealing the presence in the matrices of the two low-energy cis $\left(\mathrm{O}=\mathrm{C}-\mathrm{O}-\mathrm{C}\right.$ dihedral $\left.\sim 0^{\circ}\right)$ conformers of the compound, e.g., conformers $\mathrm{I}\left(\mathrm{C}_{s}\right.$ symmetry) and II ( $\mathrm{C}_{1}$ symmetry). These conformers exhibit anti and gauche orientations within the ester group, with the $\mathrm{C}-\mathrm{O}-\mathrm{C}-\mathrm{C}\left(\mathrm{H}_{3}\right)$ dihedral angle equal to $0^{\circ}$ and $-86.6 /+86.6^{\circ}$, respectively. Conformer I was predicted to be the most stable conformer and dominates in the studied low-temperature matrices. Interestingly, its population was found to be larger in the Ar matrix than in the $\mathrm{N}_{2}$ matrix, relatively to that of conformer II, revealing that in the Ar matrix the conformational cooling (leading to the conversion of II into I) is more extensive (correlating with the lower thermal conductivity of solid Ar compared to solid $\mathrm{N}_{2}$ ). The other two conformers (III and IV; trans forms with the $\mathrm{O}=\mathrm{C}-\mathrm{O}-\mathrm{C}$ dihedral $\sim 180.0$ ) were also predicted by the calculations, being higher in energy than the lower-energy cis conformers by about $20 \mathrm{~kJ} \mathrm{~mol}^{-1}$.

Irradiation of matrix-isolated compound (in $\mathrm{N}_{2}$ matrix) with $\mathrm{UV}$ light $(\lambda>235 \mathrm{~nm})$ yields $\mathrm{CO}$ and ethoxyethyne, with the latter compound undergoing a subsequent photoreaction that produces ketene (and ethene). 


\section{Supporting information}

Figure S1, with the DFT(B3LYP)/6-311++G(d,p) optimized structures of ethoxyethyne (EE) and ketene; Tables S1 and S2 with the DFT(B3LYP) and MP2 calculated bond lengths and angles for the four conformers of EP, Tables S3-S9 with the results of normal coordinate analysis performed for EP (conformers I and II), EE and ketene. The Supporting Information is available free of charge via the Internet at ...

\section{Acknowledgments}

The authors acknowledge the financial support from the Portuguese "Fundação para a Ciência e a Tecnologia" (FCT) (Post-doctoral Grant ref. SFRH/BPD/77276/2011 and Project PTDC/QEQ-QFI/3284/2014 - POCI-01-0145-FEDER-016617). T. N. is grateful to FCT for financial support through project PTDC/QEQ-QFI/3284/2014. The Coimbra Chemistry Centre (CQC) is also supported by FCT (Projects UI0313B/QUI/2020 and UI0313P/QUI/2020) and COMPETE-UE. We also thank Dr. Ricardo R. F. Bento (Federal University of Mato Grosso, Cuiabá, Brazil) for his technical assistance in the early stages of this work.

\section{Note}

The authors declare no competing financial interest. 


\section{References}

(1) Clark, R. D.; Untch, K. G. [2 + 2] Cycloaddition of Ethyl Propiolate and Silyl Enol Ethers. J. Org. Chem. 1979, 44, 248-253.

(2) Abu-Orabi, S. T.; Atfah, M. A.; Jibril, I.; Mari'i, F. M.; Ali, A. A.-S. Dipolar Cycloaddition Reactions of Organic Azides with Some Acetylenic Compounds. J. Heterocycl. Chem. 1989, 26 (5), 1461-1468.

(3) Tamura, B. Y.; Sumida, Y.; Miki, Y.; Ikeda, M.; Effects of 3-Substituents upon Orientation in the 1,3-Dipolar Cyclo-Addition Reaction between 3-Substituted Pyridine $\mathrm{N}$-imides and Ethyl Propiolate: Syntheses of Ethyl 4- and 6-Substituted Pyrazolo[1,5a]-Pyridine-3-Carboxylates. J. Chem. Soc. Perkin Trans. 1 1973, 406, 406-409.

(4) Suárez, A.; Downey, C. W.; Fu, G. C. Kinetic Resolutions of Azomethine Imines via Copper-Catalyzed [3 + 2] Cycloadditions. J. Am. Chem. Soc. 2005, 127, 11244-11245.

(5) Vuluga, D.; Legros, J.; Crousse, B.; Bonnet-Delpon, D. Synthesis of Pyrazoles through Catalyst-Free Cycloaddition of Diazo Compounds to Alkynes. Green Chem. 2009, 11, 156-159.

(6) Chang, C. W.; Lin, Y. C.; Lee, G. H.; Wang, Y. [3+2] Cycloaddition of Ruthenium Azido Complex with Ethyl Propiolate and Related Reactions. J. Organomet. Chem. 2018, 860, 72-77.

(7) Persson, T.; Nielsen, J. Synthesis of $N$-Methoxy- $N$-Methyl-Beta-Enaminoketoesters: New Synthetic Precursors for the Regioselective Synthesis of Heterocyclic Compounds. Org. Lett. 2006, 8, 3219-3222.

(8) Nori-Shargh, D.; Soltani, B.; Saroogh-Farahani, N.; Deyhimi, F. Kinetics and Mechanism Study of Aniline Addition to Ethyl Propiolate. Int. J. Chem. Kinet. 2006, 38, 144-151.

(9) Kim, S. I.; Baek, H. W.; Um, I. H. Kinetics and Mechanism of Michael-Type Reactions of Ethyl Propiolate with Alicyclic Secondary Amines in H2O and MeCN: Solvent Effect on Reactivity and Transition-State Structure. Bull. Korean Chem. Soc. 2009, 30, 29092912.

(10) Ogawa, A.; Doi, M.; Tsuchii, K.; Hirao, T. Selective Sequential Addition of Diphenyl Diselenide to Ethyl Propiolate and Isocyanides upon Irradiation with Near-UV Light. Tetrahedron Lett. 2001, 42, 2317-2319.

(11) Chen, D.; Timmons, C.; Liu, J.; Headley, A.; Li, G. The First Enantioselective Halo Aldol Reaction of Ethyl Propiolate and Aldehydes. Eur. J. Org. Chem. 2004, 15, 33303335.

(12) Jones, D. T.; Artman, G. D.; Williams, R. M. Coupling of Activated Esters to Gramines in the Presence of Ethyl Propiolate under Mild Conditions. Tetrahedron Lett. 2007, 48, 1291-1294.

(13) Fujimori, S.; Carreira, E. M. Cu${ }^{\mathrm{I}}$-Catalyzed Conjugate Addition of Ethyl Propiolate. Angew. Chemie - Int. Ed. 2007, 46, 4964-4967.

(14) Zacharis, C. K.; Tzanavaras, P. D.; Themelis, D. G. Ethyl-Propiolate as a Novel and Promising Analytical Reagent for the Derivatization of Thiols: Study of the Reaction under Flow Conditions. J. Pharm. Biomed. Anal. 2009, 50, 384-391. 
(15) Zacharis, C. K.; Tzanavaras, P. D.; Zotou, A. Ethyl Propiolate as a Post-Column Derivatization Reagent for Thiols: Development of a Green Liquid Chromatographic Method for the Determination of Glutathione in Vegetables. Anal. Chim. Acta 2011, 690, $122-128$.

(16) Downey, C. W.; Craciun, S.; Neferu, A. M.; Vivelo, C. A.; Mueller, C. J.; Southall, B. C.; Corsi, S.; Etchill, E. W.; Sault, R. J. One-Pot Synthesis of (Z)- $\beta$-Sulfonyl Enoates from Ethyl Propiolate. Tetrahedron Lett. 2012, 53, 5763-5765.

(17) Charles, S. W.; Jones, G. I. L.; Owen, N. L.; West, L.A. Infrared Spectra and Rotational Isomerism in Ethyl Fluoroformate and Ethyl Propiolate. J. Mol. Struct. 1975, 26, 249257.

(18) Riveros, J. M.; Wilson, Jr., E. B. Microwave Spectrum and Rotational Isomerism of Ethyl Formate. J. Chem. Phys. 1967, 46, 4605-4612.

(19) Faria, M. D. G.; Teixeira-Dias, J. J. C.; Fausto, R. Conformational Stability for Methyl Acrylate: A Vibrational Spectroscopic and Ab Initio MO Study. Vib. Spectrosc. 1991, $2,43-60$.

(20) Faria, M. D. G.; Teixeira-Dias, J. J. C.; Fausto, R. Hydrogen Bonding Involving $\alpha, \beta-$ Unsaturated Carboxylic Esters and Substituted Phenols: An Infrared Spectroscopic Study. J. Mol. Struct. 1991, 263, 87-94.

(21) Tonge, P. J.; Fausto, R.; Carey, P. R. FTIR Studies of Hydrogen Bonding between $\alpha, \beta-$ Unsaturated Esters and Alcohols. J. Mol. Struct. 1996, 379, 135-142.

(22) Neta, J. M. F.; Fausto, R. Molecular Structure and Vibrational Spectra of Methyl Cyanoacetate: An FT-IR, Raman and Ab Initio Molecular Orbital Study. J. Mol. Struct. 1998, 443, 41-56.

(23) Jarmelo, S.; Fausto, R. Molecular Structure and Vibrational Spectra of Methyl Glycolate and Methyl $\alpha$-Hydroxy Isobutyrate. J. Mol. Struct. 1999, 509, 183-199.

(24) Gómez-Zavaglia, A.; Fausto, R. Low Temperature FT-IR and Molecular Orbital Study of $N, N$-Dimethylglycine Methyl Ester: Proof for Different Ground Conformational States in Gas Phase and in Condensed Media. Phys. Chem. Chem. Phys. 2003, 5, 52-63.

(25) Borba, A.; Gómez-Zavaglia, A.; Lapinski, L.; Fausto, R. Matrix Isolation FTIR Spectroscopic and Theoretical Study of Methyl Lactate. Vibrat. Spectrosc. 2004, 36, 7988 .

(26) Frisch, M. J.; Trucks, G. W.; Schlegel, H. B.; Scuseria, G. E.; Robb, M. A.; Cheeseman, J. R.; Scalmani, G.; Barone, V.; Mennucci, B.; Petersson, G. A.; et al. Gaussian 09, Revision A.02. Gaussian, Inc.: Wallingford, CT 2009.

(27) Frisch, M. J.; Trucks, G. W.; Schlegel, H. B.; Scuseria, G. E.; Robb, M. A.; Cheeseman, J. R.; Scalmani, G.; Barone, V.; Mennucci, B.; Petersson, G. A.; et al. Gaussian 09, Revision D.01. Gaussian, Inc.: Wallingford, CT 2009.

(28) Vosko, S. H.; Wilk, L.; Nusair, M. Accurate Spin-Dependent Electron Liquid Correlation Energies for Local Spin Density Calculations: A Critical Analysis. Can. J. Phys. 1980, 58, 1200-1211.

(29) Becke, A. D. Density-Functional Exchange-Energy Approximation with Correct Asymptotic Behavior. Phys. Rev. A 1988, 38, 3098-3100. 
(30) Lee, C.; Yang, W.; Parr, R. G. Development of the Colle-Salvetti Correlation-Energy Formula into a Functional of the Electron Density. Phys. Rev. B 1988, 37, 785-789.

(31) Møller, C.; Plesset, M. S. Note on an Approximation Treatment for Many-Electron Systems. Phys. Rev. 1934, 46, 618-622.

(32) McLean, A. D.; Chandler, G. S. Contracted Gaussian Basis Sets for Molecular Calculations. I. Second Row Atoms, $Z=11-18$. J. Chem. Phys. 1980, 72, 5639-5648.

(33) Krishnan, R.; Binkley, J. S.; Seeger, R.; Pople, J. A. Self-Consistent Molecular Orbital Methods. XX. A Basis Set for Correlated Wave Functions. J. Chem. Phys. 1980, 72, $650-654$.

(34) Frisch, M. J.; Pople, J. A.; Binkley, J. S. Self-Consistent Molecular Orbital Methods 25. Supplementary Functions for Gaussian Basis Sets. J. Chem. Phys. 1984, 80, 3265-3269.

(35) Hammoum, R.; Fontana, M. D.; Bourson, P.; Shur, V. Y. Characterization of PPLNMicrostructures by Means of Raman Spectroscopy. Appl. Phys. A 2008, 91, 65-67.

(36) Dunning, T. H. Gaussian Basis Sets for Use in Correlated Molecular Calculations. I. The Atoms Boron through Neon and Hydrogen. J. Chem. Phys. 1989, 90, 1007-1023.

(37) Kendall, R. A.; Dunning, T. H.; Harrison, R. J. Electron Affinities of the First-row Atoms Revisited. Systematic Basis Sets and Wave Functions. J. Chem. Phys. 1992, 96, 6796-6806.

(38) Woon, D. E.; Dunning, T. H. Gaussian Basis Sets for Use in Correlated Molecular Calculations. III. The Atoms Aluminum through Argon. J. Chem. Phys. 1993, 98, 13581371.

(39) Davidson, E. R. Comment on "Comment on Dunning's Correlation-Consistent Basis Sets." Chem. Phys. Lett. 1996, 260, 514-518.

(40) Peng, C.; Bernhard Schlegel, H. Combining Synchronous Transit and Quasi-Newton Methods to Find Transition States. Isr. J. Chem. 1993, 33, 449-454.

(41) Schachtschneider, J. H. Vibrational Analysis of Polyatomic Molecules, VI: FORTRAN IV Programs for Solving the Vibrational Secular Equation and for the Least-Squares Refinement of Force Constants; Shell Development Company, 1965.

(42) Pulay, P.; Fogarasi, G.; Pang, F.; Boggs, J. E. Systematic Ab Initio Gradient Calculation of Molecular Geometries, Force Constants, and Dipole Moment Derivatives. J. Am. Chem. Soc. 1979, 101, 2550-2560.

(43) Reva, I.; Simão, A.; Fausto, R. Conformational Properties of Trimethyl Phosphate Monomer. Chem. Phys. Lett. 2005, 406, 126-136.

(44) Reva, I. D.; Stepanian, S. G.; Adamowicz, L.; Fausto, R. Missing Conformers. Comparative Study of Conformational Cooling in Cyanoacetic Acid and Methyl Cyanoacetate Isolated in Low Temperature Inert Gas Matrices". Chem. Phys. Lett. 2003, 374, 631-638.

(45) Borba, A.; Gómez-Zavaglia, A.; Fausto, R. Conformational Cooling and Conformation Selective Aggregation in Dimethyl Sulfite Isolated in Solid Rare Gases. J. Mol. Struct. 2006, 794, 196-203.

(46) Rosado, M. T. S.; Jesus, A. J. L.; Reva, I. D.; Fausto, R.; Redinha, J. S. Conformational Cooling Dynamics in Matrix-isolated 1,3-Butanediol. J. Phys. Chem. A 2009, 113, 7499-7507. 
(47) Jovan Jose, K. V.; R. Gadre, S.; Sundararajan, K.; Viswanathan, K. S. Effect of matrix on IR frequencies of acetylene and acetylene-methanol complex: Infrared matrixisolation and ab initio study. J. Chem. Phys. 2007, 127, 104501.

(48) Anderson, D. T.; Winn, J. S. Infrared Spectrum of Matrix-Isolated CO and CO Photoproduct from OCS Photolysis. J. Phys. Chem. A 2000, 104, 3472-3480.

(49) Maki, A. G. Infrared Spectra of Carbon Monoxide as a Solid and in Solid Matrices. J. Chem. Phys. 1961, 35, 931-935.

(50) Duncan, J. L.; Ferguson, A. M.; Harper, J.; Tonge, K. H. A Combined Empirical-Ab Initio Determination of the General Harmonic Force Field of Ketene. J. Mol. Spectrosc. 1987, 125, 196-213.

(51) Moore, C. B.; Pimentel, G. C. Infrared Spectrum and Vibrational Potential Function of Ketene and the Deuterated Ketenes. J. Chem. Phys. 1963, 38, 2816-2829.

(52) East, A. L. L.; Allen, W. D.; Klippenstein, S. J. The Anharmonic Force Field and Equilibrium Molecular Structure of Ketene. J. Chem. Phys. 1995, 102, 8506-8532.

(53) Krisch, M. J.; Miller, J. L.; Butler, L. J.; Su, H.; Bersohn, R.; Shu, J. Photodissociation Dynamics of Ethyl Ethynyl Ether: A New Ketenyl Radical Precursor. J. Chem. Phys. 2003, 119, 176-186.

(54) Wilhelm, M. J.; McNavage, W.; Groller, R.; Dai, H. L. The $v_{1}$ CH Stretching Mode of the Ketenyl (HCCO) Radical. J. Chem. Phys. 2008, 128, 064313-8.

(55) Wilhelm, M. J.; McNavage, W.; Smith, J. M.; Dai, H. L. The Lowest Quartet-State of the Ketenyl (HCCO) Radical: Collision-Induced Intersystem Crossing and the $v_{2}$ Vibrational Mode. Chem. Phys. 2013, 422, 290-296.

(56) Zvereva-Loëte, N.; Ballandras, A.; Weber, G.; Rotger, M.; Boudon, V. Experimental IR Study and ab initio Modelling of Ethylene Adsorption in a MFI-type Host Zeolite. Mol. Phys. 2009, 107, 2081-2093. 